\title{
Physician Consultation, Multidisciplinary Care, and 1-Year Mortality in Medicare Recipients Hospitalized with Hip and Lower Extremity Injuries
}

\author{
(See Editorial Comments by Dr. David B. Reuben, pp 2022-2023)
}

\author{
Annette L. Adams, PhD, MPH, ${ }^{* \dagger}$ Melissa A. Schiff, MD, MPH, ${ }^{* \dagger}$ Thomas D. Koepsell, MD, MPH, ${ }^{* \ddagger}$ \\ Frederick P. Rivara, MD, MPH, ${ }^{*}+\mathcal{S}$ Brian G. Leroux, PhD, "Thomas M. Becker, MD, PhD, " and \\ Jerris R. Hedges, $M D^{\dagger * *}$
}

\begin{abstract}
OBJECTIVE: To determine whether routine surgeon consultation with medicine specialists and multidisciplinary care conferences - potentially modifiable hospital characteristics-are associated with lower 1-year mortality in older adults with hip and lower extremity injuries.
\end{abstract}

DESIGN: Retrospective cohort study.

SETTING: Oregon hospitals.

PARTICIPANTS: Two thousand five hundred thirty-eight Medicare recipients aged 67 and older hospitalized in Oregon hospitals in 2002 with hip or lower extremity injuries.

MEASUREMENTS: Demographic, injury, comorbidity, and survival information were gathered from Medicare records for 2000 to 2003. All Oregon hospitals with a qualifying case were surveyed using a structured telephone interview to collect information about routine surgeon consultations and multidisciplinary care conferences for older adult orthopedic patients. Multivariable generalized estimating equation models were used to estimate odds ratios (ORs) and 95\% confidence intervals (CIs) for the associations between hospital characteristics and mortality.

RESULTS: After adjusting for age, injury severity, comorbid conditions, trauma center status, and hospital annual volume of patients with hip fracture, the relative odds of dying in the year after injury for inpatients treated in settings with routine surgeon consultation with medical staff was $0.69(95 \%$ CI $0.57-0.83)$ compared with patients not treated in such settings. Inpatient treatment in settings with

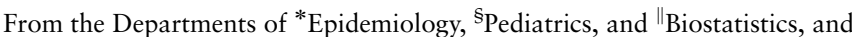
${ }^{\ddagger}$ Harborview Injury Prevention and Research Center, University of Washington, Seattle, Washington; Departments of "Public Health and Preventive Medicine and ${ }^{\dagger}$ Emergency Medicine, Oregon Health \& Science University, Portland, Oregon; and ** John A. Burns School of Medicine, University of Hawaii-Manoa, Honolulu, Hawaii.

Address correspondence to Annette L. Adams, Research and Evaluation, Southern California Permanente Medical Group, 100 S. Los Robles, 2nd floor, Pasadena, CA 91107. E-mail: Annette.L.Adams@kp.org

DOI: $10.1111 / \mathrm{j} .1532-5415.2010 .03087 . x$ routine multidisciplinary care conferences did not significantly affect the relative odds of dying in the year after injury $(\mathrm{OR}=1.06,95 \% \mathrm{CI}=0.89-1.26)$.

CONCLUSION: Routine consultation by attending orthopedic surgeons with medicine or primary care specialists for Medicare inpatients is associated with better survival 1 year after injury. J Am Geriatr Soc 58:1835-1842, 2010.

Key words: Medicare; hip fracture; mortality; integrated care

I njuries to elderly persons represent a substantial public health problem, one that will be exacerbated as the U.S. population ages. Hip fractures and other lower extremity injuries are common in persons aged 65 and older, ${ }^{1}$ hamper an individual's ability to maintain independent living, ${ }^{2-6}$ and are a major threat to survival. ${ }^{7-13}$

Considerable literature exists regarding the clinical treatment of such injuries and the patient characteristics that may contribute to better or worse outcomes. Research on patient characteristics focuses on factors that are not easily modifiable, such as age, ${ }^{14-16}$ sex,,${ }^{9,15-17}$ and comorbid conditions. ${ }^{9,15-17}$ Some investigators have also examined hospital- and community-level factors that may influence patient outcomes, such as specialized elder-care units, ${ }^{18}$ the number of hospitals in a county, ${ }^{19}$ hospital size,${ }^{19-21}$ and the number of physicians in a county, ${ }^{19}$ but many such factors are also not easily modifiable.

Much less attention has been focused on potentially modifiable factors that could mitigate the effect of these less-modifiable factors - for example, the effect that integration of care in the hospital setting, using the expertise of medicine or geriatric specialists to assist the surgeon with 
the care of the patient, might have on outcomes such as death in the postinjury period. For example, previous studies have shown some evidence that hospitalist management of medical inpatients may result in better survival ${ }^{22-24}$ and shorter length of stay. ${ }^{22-25}$ For patients with hip fracture, management by hospitalists also resulted in shorter time to surgery ${ }^{26}$ shorter length of stay, ${ }^{26}$ and fewer complications. ${ }^{27}$ Similarly, orthopedist and geriatrician comanagement has been associated with lower in-hospital mortality 28 and fewer complications ${ }^{28,29}$ and rehospitalizations. ${ }^{28}$

The overall objective of this study was to examine the relationships between two potentially modifiable hospitallevel processes and outcomes in elderly patients hospitalized for lower extremity injuries. Specifically, this study sought to measure the extent to which routine consultation by the surgeon with an internist, hospitalist, or primary care physician was associated with lower mortality during the year after the index injury. The study also sought to estimate the extent to which patients treated in a milieu where routine multidisciplinary care conferences were held had reduced mortality at 1 year after injury.

\section{METHODS}

\section{Study Design and Study Subjects}

Eligible subjects for this retrospective cohort study were identified from fee-for-service Medicare recipients who were hospitalized in 2002 in any Oregon hospital with a qualifying lower extremity or acetabular injury. Eligible subjects were aged 67 and older at the time of the index hospitalization to ensure that at least 2 years of preinjury records could be evaluated for each subject. Relevant injury hospitalizations were identified from Medicare claims data using International Classification of Diseases, Ninth Revision, Clinical Modification (ICD-9-CM) discharge diagnosis codes 808.0 to 808.1 (acetabulum fracture), 820 to 829.1 (fractures of lower limbs), 835 to 838.19 (dislocations of hip, knee, ankle, or foot), or 843 to 845.19 (sprains or strains of hip, thigh, knee, leg, ankle, or foot). Hospitalizations for which a qualifying injury was listed as the first of all injury diagnoses were considered to be index hospitalizations. Hospitalizations for multiple, nonindex injuries, such as those sustained in an automobile crash, were not included as index hospitalizations. Hospitalizations for qualifying injuries but that occurred in the 6 months after another injury hospitalization with diagnosis codes indicating similar injuries or similar affected body parts were considered to be rehospitalizations for the original injury and were ineligible as index hospitalizations. For courses of treatment that included interhospital transfers, the index hospital was chosen to be the one for which the disposition code indicated an end to acute care.

The Oregon Health \& Science University institutional review board and the Centers for Medicare and Medicaid Services (CMS) Privacy Board approved this study with a Health Information Portability and Accountability Act waiver of consent.

\section{Data Sources}

Patient-level data were obtained from CMS. Cohort members were identified from the 2002 National Medical Provider and Analysis Review (MedPAR) file containing records of inpatient hospital stays. All MedPAR records for 2000 to 2003 were retained for each cohort member identified. All Medicare records for 2000 to 2003 were also obtained from the following CMS databases for all cohort members: the Outpatient Standard Analytic file, containing claims data submitted by institutional outpatient providers; the Carrier file, containing claims submitted by noninstitutional providers; and the Denominator file, which includes demographic and enrollment information for each Medicare beneficiary. Thus, for each cohort member, medical resource utilization records were obtained for at least 2 years before and at least 1 year after the index hospitalization.

A single researcher collected hospital-level data in a telephone interview using a standard survey instrument consisting largely of multiple-choice questions. An attempt was made to survey each of Oregon's 61 hospitals at which an eligible patient was treated. For all but two hospitals, the charge nurse of the surgical or medical-surgical unit where these patients were treated was interviewed. For the two hospitals where a charge nurse was not available or could not be reached in a timely manner, a social worker or discharge planner was interviewed. Hospital-level data of interest included information about the wards in which geriatric orthopedic patients were treated (medical vs surgical), types of physicians or care providers who could be called upon for consultations related to management of medical conditions and comorbid conditions, presence of geriatricians on hospital staff or available to surgeons as consultants, whether multidisciplinary care conferences were held for every elderly orthopedic patient or only "when needed," and the specialties of the care providers who were expected to participate in such care conferences. The treating hospital for each cohort member was identifiable, and the hospital-level data were linked to the individual Medicare records.

Additional hospital- and community-level data were collected from publicly available sources such as census data, ${ }^{30}$ the Oregon Association of Hospitals and Health Systems Web site, ${ }^{31}$ the Oregon Trauma System Web site, ${ }^{32}$ and the Oregon Health Policy and Research Web site. ${ }^{33}$ From these sources, the following hospital-level information was gathered: number of licensed and staffed beds, annual volume of surgeries, annual volume of emergency department visits, annual number of inpatient days, annual number of outpatient visits, numbers of hip fracture patients treated in 2004 , and the hospital's trauma system designation by the state. The following community- and county-level information was also gathered: median annual county income and the proportion of county residents aged 65 and older.

\section{Exposure Variables}

Two primary exposures of interest were examined. Information from the hospital questionnaire was used to identify exposure status for each hospital. The first exposure, called "routine consultation," reflects a hospital's capacity to provide orthopedic care integrated with medical care through consultations between the surgeon and a geriatrician (where available); a hospitalist; an internist; another hospital-based medicine specialist, such as a physician assistant; or the patient's primary care physician. Such consultations were considered "routine" if the charge nurse interviewed for the hospital survey (or his or her surrogate) indicated that such consultations were "always" sought, regardless of individual 
case characteristics. For hospitals with multiple units within which eligible patients could be treated, it was attempted to gather information about the unit where patients meeting the case criteria were most likely to be treated.

The second exposure of interest was whether the patient's lower extremity injury was treated in a hospital where multidisciplinary care conferences were routine for these patients, meaning that every patient was discussed in at least one of these multidisciplinary meetings during the course of their inpatient treatment. Multidisciplinary care conferences were defined as regularly occurring care conferences or meetings that involved heathcare professionals other than the attending or consulting physicians (e.g., nursing, pharmacy, social work, physical and occupational therapists). More specifically, a care conference was defined as being multidisciplinary if the attendance of the following professionals was expected and was considered by the interview source to be routine, not just on an "as needed" basis: nursing, physical or occupational therapy, and social work or discharge planning. At no hospital for which survey information was gathered was physician attendance at these care meetings expected or considered "routine," so physician involvement was not included in the definition.

\section{Outcome Variable}

The outcome variable of primary interest was death from any cause within 1 year of the index hospital admission date, which was used as a surrogate for date of injury. Dates of death were recorded in the MedPAR and Denominator files. Death dates for all cohort members were obtained from both sources and compared for consistency. No discrepancies were noted between these two data sources.

\section{Covariates}

Patient age, sex, race, comorbid conditions, and injury severity were identified a priori as patient-level factors to be assessed as potential confounders of the associations between each of the two exposures and death 1 year postinjury. Comorbid and preexisting medical conditions for all subjects were ascertained using ICD-9 diagnostic codes from inpatient claims records from the 2 years before the index hospitalization and outpatient claims records for 1 year before index hospitalization, as described previously, ${ }^{34}$ and were summarized using an adaptation of the Charlson method ${ }^{35}$ described by Deyo and colleagues. ${ }^{36}$ For purposes of analysis, the Deyo score was categorized as 0,1 to 2 , and 3 or more. Injury severity was estimated using the ICD-9-based Injury Severity Score (ICISS), ${ }^{37-40}$ an estimate of the probability of survival given an individual's unique pattern of injuries.

Hospital- and community-level characteristics that were evaluated as potential confounders were trauma center status (Level I or II, Level III or IV, or not designated), annual hip fracture patient volume $(<30,30-99$, and $\geq 100)$, rurality of hospital $^{41}$ (small and remote, small and rural, rural, and urban), number of hospital beds $(<50,50-250$, or $>250)$, number of orthopedic surgeons in the county $(<5,5-20$, and $>20)$, median annual county income $(<\$ 35,000, \$ 35,000$ $\$ 40,000$, and $>\$ 40,000)$, and proportion of the community aged 65 and older $(<12 \%, 12-18 \%$, and $>18 \%$ ).
In addition to their potential confounding effect, age, sex, and Deyo score were considered a priori to be potential effect modifiers.

\section{Statistical Analysis}

Mortality was modeled as a binary outcome, indicating whether the patient was alive 1 year postinjury. The associations between the exposures of interest, routine consultation and multidisciplinary care conferences, and the outcome were evaluated using generalized estimating equations ${ }^{42}$ to account for possible clustering according to hospital. In addition to modeling each exposure's association with the outcome separately, both exposures were modeled simultaneously in a single statistical model to adjust each exposure for the presence of the other. Further adjustment for other potential confounders was conducted as described below.

Covariates that altered the coefficient for the primary predictor of interest by more than $10 \%$ from the unadjusted estimate were retained in the models. The final unstratified model included adjustment for age, ICISS, Deyo score, trauma center status, volume of patients with hip fracture, county median household income, and county proportion of population aged 65 and older. Age, sex, and Deyo score were assessed as potential effect modifiers as well. Age and sex did not appear to modify the associations of interest, as assessed according to the statistical significance of a multiplicative interaction term, but Deyo score did. Thus, estimates stratified according to Deyo score category are also presented.

Associations between the exposures and the mortality outcome are reported as odd ratios (ORs) with $95 \%$ confidence intervals (CIs). All data management and statistical analyses were conducted using Stata, version 10 (StataCorp, College Station, TX).

\section{RESULTS}

In 2002, there were 2,804 Medicare recipients hospitalized in Oregon hospitals with qualifying injuries. Fifty-three of the 57 hospitals $(93 \%)$ that treated a qualifying cohort member completed the telephone survey, providing hospital-level exposure data for 2,538 of the 2,804 eligible subjects. Of the four hospitals for which exposure information was not collected, one had closed between the time the patient was treated and the time this survey was conducted, and three did not respond to requests for interviews. Of the hospitals for which exposure data were collected, 45 $(84.9 \%)$ reported that medicine consultations were the norm for these patients, and $14(26.4 \%)$ reported holding routine multidisciplinary care conferences (Table 1).

The study cohort had a mean age of $83.1 \pm 7.6 ; 98.0 \%$ were white, and $72.7 \%$ were female (Table 1 ). Two thousand eighty-three subjects $(82.1 \%)$ had a single injury - the index injury and no other injuries. For $76.2 \%$ of the cohort, the index injury was a fracture of the neck of the femur.

The most common comorbid condition was chronic pulmonary disease $(25.2 \%)$, followed by congestive heart failure $(22.7 \%)$ and diabetes mellitus $(19.4 \%)$. Death within 1 year of the index hospitalization was common ( $\mathrm{n}=702,27.7 \%)$, with 79 patients $(3.1 \%)$ dying during the index hospitalization. Routine consultation was also common, with $92.0 \%(\mathrm{n}=2,335)$ of the cohort being treated 
Table 1. Demographic, Injury, and Comorbidity Characteristics for Fee-for-Service Medicare Beneficiaries Aged 67 and Older at the Time of Hospitalization for a Hip or Lower Extremity Injury, Oregon, 2002

n (\%)

\begin{tabular}{|c|c|c|c|c|c|}
\hline \multirow[b]{2}{*}{ Characteristic } & \multirow{2}{*}{$\begin{array}{l}\text { All Subjects } \\
N=2,538\end{array}$} & \multicolumn{2}{|c|}{ Routine Consultation } & \multicolumn{2}{|c|}{$\begin{array}{l}\text { Multidisciplinary Care } \\
\text { Conferences }\end{array}$} \\
\hline & & $\begin{array}{c}\text { Yes } \\
\mathbf{n}=\mathbf{2 , 3 3 5}\end{array}$ & $\begin{array}{c}\text { No } \\
n=203\end{array}$ & $\begin{array}{c}\text { Yes } \\
n=680\end{array}$ & $\begin{array}{c}\text { No } \\
n=1,858\end{array}$ \\
\hline Hospitals & $53(100.0)$ & $45(84.9)$ & $8(15.1)$ & $14(26.4)$ & 39 (73.6) \\
\hline \multicolumn{6}{|l|}{ Age } \\
\hline $67-74$ & $380(15.0)$ & $351(15.0)$ & $29(14.3)$ & $94(13.8)$ & $286(15.4)$ \\
\hline $75-84$ & $993(39.1)$ & $911(39.0)$ & $82(40.4)$ & $265(39.0)$ & $728(39.2)$ \\
\hline$\geq 85$ & $1,165(45.9)$ & $1,073(45.9)$ & $92(45.3)$ & $321(47.2)$ & $844(45.4)$ \\
\hline Female & $1,844(72.7)$ & $1,707(73.1)$ & $137(67.5)$ & $507(74.6)$ & $1,337(72.0)$ \\
\hline White & $2,486(98.0)$ & 2,287 (97.9) & $199(98.0)$ & 670 (98.5) & $1,816(97.7)$ \\
\hline \multicolumn{6}{|l|}{ Type of index injury } \\
\hline Fracture, femur, neck & $1,935(76.2)$ & $1,789(76.2)$ & $146(71.9)$ & $530(77.9)$ & $1,405(75.6)$ \\
\hline Fracture, lower limb, other* & $346(13.6)$ & $307(13.1)$ & $39(19.2)$ & $95(14.0)$ & $251(13.5)$ \\
\hline Fracture, femur, other & $122(4.8)$ & $115(4.9)$ & $7(3.5)$ & $26(3.8)$ & $96(5.2)$ \\
\hline Sprain, strain, or dislocation & $79(3.1)$ & $73(3.1)$ & $6(3.0)$ & $19(2.8)$ & $60(3.2)$ \\
\hline Fracture, acetabulum & $56(2.2)$ & $51(2.2)$ & $5(2.5)$ & $10(1.5)$ & $46(2.5)$ \\
\hline \multicolumn{6}{|l|}{ Comorbidities $^{\dagger}$} \\
\hline Chronic pulmonary disease & $639(25.2)$ & $599(25.7)$ & $40(19.7)$ & $176(25.9)$ & $463(24.9)$ \\
\hline Congestive heart failure & $575(22.7)$ & $536(23.0)$ & $39(19.2)$ & $165(24.3)$ & $410(22.1)$ \\
\hline Diabetes mellitus & $491(19.4)$ & $450(19.3)$ & $41(20.2)$ & $130(19.1)$ & $361(19.4)$ \\
\hline Cerebrovascular disease & $390(15.4)$ & $369(15.8)$ & $21(10.3)$ & $91(13.4)$ & $299(16.1)$ \\
\hline Dementia & $295(11.6)$ & $273(11.7)$ & $22(10.8)$ & 77 (11.3) & $218(11.7)$ \\
\hline Myocardial infarction & $232(9.1)$ & $222(9.5)$ & $10(4.9)$ & $52(7.7)$ & $180(9.7)$ \\
\hline Any malignancy & $203(8.0)$ & $189(8.1)$ & $14(6.9)$ & $54(7.9)$ & $149(8.0)$ \\
\hline Peripheral vascular disease & $166(6.5)$ & $151(6.5)$ & $15(7.4)$ & $49(7.2)$ & $117(6.3)$ \\
\hline \multicolumn{6}{|l|}{ Deyo comorbidity score ${ }^{\ddagger}$} \\
\hline 0 & $1,139(44.9)$ & $1,036(44.4)$ & $103(50.7)$ & $307(45.1)$ & $832(44.8)$ \\
\hline 1 or 2 & $989(39.0)$ & $912(39.1)$ & $77(37.9)$ & $258(37.9)$ & 731 (39.3) \\
\hline$\geq 3$ & $410(16.1)$ & 387 (16.6) & $23(11.3)$ & $115(16.9)$ & 295 (15.9) \\
\hline Died during index hospitalization & $79(3.1)$ & $70(3.0)$ & $9(4.4)$ & $24(3.5)$ & $55(3.0)$ \\
\hline Died within 1 year of index admission & $702(27.7)$ & $636(27.2)$ & $66(32.5)$ & $195(28.7)$ & 507 (27.3) \\
\hline
\end{tabular}

* Fractures of the ankle, tibia or fibula, foot, patella, or other unspecified lower limb fracture.

${ }^{\dagger}$ These numbers may total to greater than $100 \%$. Some subjects had more than one comorbidity identified. Comorbid conditions included in the Deyo score but that affected fewer than $5 \%$ of the cohort members (rheumatologic disease, diabetes mellitus with chronic complications, renal disease, hemi- or paraplegia, peptic ulcer disease, metastatic cancer, liver disease, human immunodeficiency virus, and acquired immunodeficiency syndrome) are not listed in the table.

${ }^{\ddagger}$ A Deyo score of 0 indicates no comorbidity, a score of 1 or 2 indicates moderate comorbid burden, and 3 or greater indicates severe comorbid burden.

in such settings where this was reported to be routine. Multidisciplinary care conferences were less common, with $26.8 \%(\mathrm{n}=680)$ of subjects being treated in wards in which this practice was described as routine. Distributions of patient-level characteristics did not appear to vary according to exposure status.

The Oregon hospitals for which surveys were completed $(\mathrm{n}=53)$ ranged in size from six to 482 staffed beds. Forty-one percent $(\mathrm{n}=22)$ of the hospitals were considered to be urban hospitals, with $20.7 \%(\mathrm{n}=11)$ being small $(<50$ beds) and remote $(>30$ miles from another hospital) (Table 2). Twelve $(22.6 \%)$ of the hospitals treated 100 or more patients with hip fracture per year; another $35 \%$ treated between 30 and 99 annually. Approximately $70 \%$ of the hospitals participating in the survey $(\mathrm{n}=37)$ were designated as Level III or IV trauma centers (Table 2). Of the 53 hospitals, 45 (78.9\%) indicated that consultations with medical or primary care providers $(n=20,37.7 \%)$ was routine for all elderly orthopedic patients. The hospitals without routine consultation $(\mathrm{n}=8)$ tended to be smaller $(75 \%$ with $<50$ beds vs $55.6 \%)$ and more rural $(62.5 \%$ small and remote vs $13.3 \%)$, and were located in communities that were older $(37.5 \%$ vs $24.4 \%$ in counties with $>18 \%$ of the population $\geq 65$ ) and poorer $(50.0 \%$ vs $28.9 \%$ in counties with median income $<\$ 35,000$ ) (Table 2). Multidisciplinary care conferences were routine for elderly orthopedic patients in 14 hospitals (26.4\%). Hospitals with multidisciplinary care conferences tended to be smaller, more rural, and in counties with slightly younger populations and have fewer orthopedic surgeons in the county and lower annual hip fracture volumes (Table 2). 
Table 2. Characteristics of Hospitals and Communities According to Exposure Group

$n(\%)$

\begin{tabular}{|c|c|c|c|c|c|}
\hline \multirow[b]{2}{*}{ Characteristic } & \multirow{2}{*}{$\begin{array}{c}\text { All Hospitals } \\
\mathbf{N}=\mathbf{5 3}\end{array}$} & \multicolumn{2}{|c|}{ Routine Consultation } & \multicolumn{2}{|c|}{ Multidisciplinary Care Conferences } \\
\hline & & $\begin{array}{c}\text { Yes } \\
n=45\end{array}$ & $\begin{array}{c}\text { No } \\
n=8\end{array}$ & $\begin{array}{c}\text { Yes } \\
n=14\end{array}$ & $\begin{array}{c}\text { No } \\
\mathbf{n}=39\end{array}$ \\
\hline Patients & $2,358(100.0)$ & 2,335 (99.0) & $203(1.0)$ & $680(28.8)$ & 1,858 (71.2) \\
\hline \multicolumn{6}{|l|}{ Licensed beds, $\mathrm{n}$} \\
\hline$<50$ & $31(58.5)$ & $25(55.6)$ & $6(75.0)$ & $12(85.7)$ & $19(48.7)$ \\
\hline $50-250$ & $14(26.4)$ & $12(26.7)$ & $2(25.0)$ & $0(0)$ & $14(35.9)$ \\
\hline$>250$ & $8(15.1)$ & $8(17.8)$ & $0(0)$ & $2(14.3)$ & $6(15.4)$ \\
\hline \multicolumn{6}{|l|}{ Trauma center status } \\
\hline Level I or II & $5(9.4)$ & $4(8.9)$ & $1(12.5)$ & $1(7.1)$ & $4(10.3)$ \\
\hline Level III or IV & $37(69.8)$ & $31(68.9)$ & $6(75.0)$ & $12(85.7)$ & $25(64.1)$ \\
\hline Nondesignated & $11(20.8)$ & $10(22.2)$ & $1(12.5)$ & $1(7.1)$ & $10(25.6)$ \\
\hline \multicolumn{6}{|l|}{ Rurality } \\
\hline Small and remote & $11(20.7)$ & $6(13.3)$ & $5(62.5)$ & $2(14.3)$ & $9(23.1)$ \\
\hline Small and rural & $18(34.0)$ & $17(37.8)$ & $1(12.5)$ & $6(42.9)$ & $12(30.8)$ \\
\hline Rural & $2(3.8)$ & $2(4.4)$ & $0(0)$ & $0(0)$ & $2(5.1)$ \\
\hline Urban & $22(41.5)$ & $20(44.4)$ & $2(25.0)$ & $6(42.9)$ & $16(41.0)$ \\
\hline \multicolumn{6}{|c|}{ Proportion of county aged $\geq 65, \%$} \\
\hline$<12$ & $15(28.3)$ & $14(31.1)$ & $1(12.5)$ & $0(0)$ & $15(38.5)$ \\
\hline $12-18$ & $24(45.3)$ & $20(44.4)$ & $4(50.0)$ & $11(78.6)$ & $13(33.3)$ \\
\hline$>18$ & $14(26.4)$ & $11(24.4)$ & $3(37.5)$ & $3(21.4)$ & $11(28.2)$ \\
\hline \multicolumn{6}{|c|}{ Median county income, \$ } \\
\hline$<35,000$ & $17(32.0)$ & $13(28.9)$ & $4(50.0)$ & $3(21.4)$ & $14(35.9)$ \\
\hline $35,000-40,000$ & $18(34.0)$ & $17(37.8)$ & $1(12.5)$ & $11(78.6)$ & $7(17.9)$ \\
\hline$>40,000$ & $18(34.0)$ & $15(33.3)$ & $3(37.5)$ & $0(0)$ & $18(46.2)$ \\
\hline \multicolumn{6}{|c|}{ Orthopedic surgeons in county, $\mathrm{n}$} \\
\hline$<5$ & $21(39.6)$ & $15(33.3)$ & $6(75.0)$ & $10(71.4)$ & $11(28.2)$ \\
\hline $5-20$ & $13(24.5)$ & $13(28.9)$ & $0(0)$ & $3(21.4)$ & $10(25.6)$ \\
\hline$>20$ & $19(35.9)$ & $17(37.8)$ & $2(25.0)$ & $1(7.1)$ & $18(46.2)$ \\
\hline \multicolumn{6}{|c|}{ Annual volume of hip fracture cases, 2004} \\
\hline$<30$ & $22(41.5)$ & $16(35.6)$ & $6(75.0)$ & $8(57.1)$ & $14(35.9)$ \\
\hline $30-99$ & $19(35.9)$ & $18(40.0)$ & $1(12.5)$ & $4(28.6)$ & $15(38.5)$ \\
\hline$\geq 100$ & $12(22.6)$ & $11(22.4)$ & 1 (12.5) & $2(14.3)$ & $10(25.6)$ \\
\hline
\end{tabular}

The relative odds of dying within the 1 year after injury were lower for patients treated in hospitals with routine consultations than for those treated in hospitals without routine consultations $(\mathrm{OR}=0.69,95 \% \mathrm{CI}=0.57-0.83)$, after adjusting for age at the time of injury, Deyo comorbidity score, ICISS, trauma center status, annual hip fracture volume, county median household income, proportion of county population aged 65 and older, and the presence of the multidisciplinary care conference exposure (Table 3). Twenty-seven percent of patients treated in the routine consultation setting died within 1 year, compared with $32.5 \%$ of patients not treated in such a setting (Table 3 ). The relative odds of dying within 1 year after injury were equivalent for subjects treated in hospitals that routinely held multidisciplinary care conferences and those not treated in such settings $(\mathrm{OR}=1.06,95 \% \mathrm{CI}=0.89$ 1.26), after adjusting for the same covariates described previously (Table 3 ).
Considering the possibility that different levels of comorbidity may modify the effect that routine consultations or multidisciplinary care conferences may have on survival, the associations for each of the different Deyo comorbidity subgroups were estimated. Within subgroups defined according to categorized Deyo score, the relative odds of death were lower for subjects treated in settings with routine medical consultation than for patients not treated in such settings (Table 3 ). The relative odds were lowest for those with Deyo score of 3 or more $(\mathrm{OR}=0.44$, $95 \% \mathrm{CI}=0.25-0.79$ ). The effect of multidisciplinary care conferences on the relative odds of death were not statistically significant for any Deyo category subgroup (Table 3 ).

\section{DISCUSSION}

This study suggests that the relative odds of death are lower for older persons hospitalized with hip or lower extremity 
Table 3. Unadjusted and Adjusted Estimates of the Association Between Hospital-Level Exposure to Routine Consultation and Multidisciplinary Care Conferences and 1-Year Mortality for Patients Aged 67 and Older Hospitalized in Oregon with Lower Extremity Injuries in 2002

$\mathrm{n}(\%)$

Model

Exposed, Died Unexposed, Died Odds Ratio (95\% Confidence Interval)

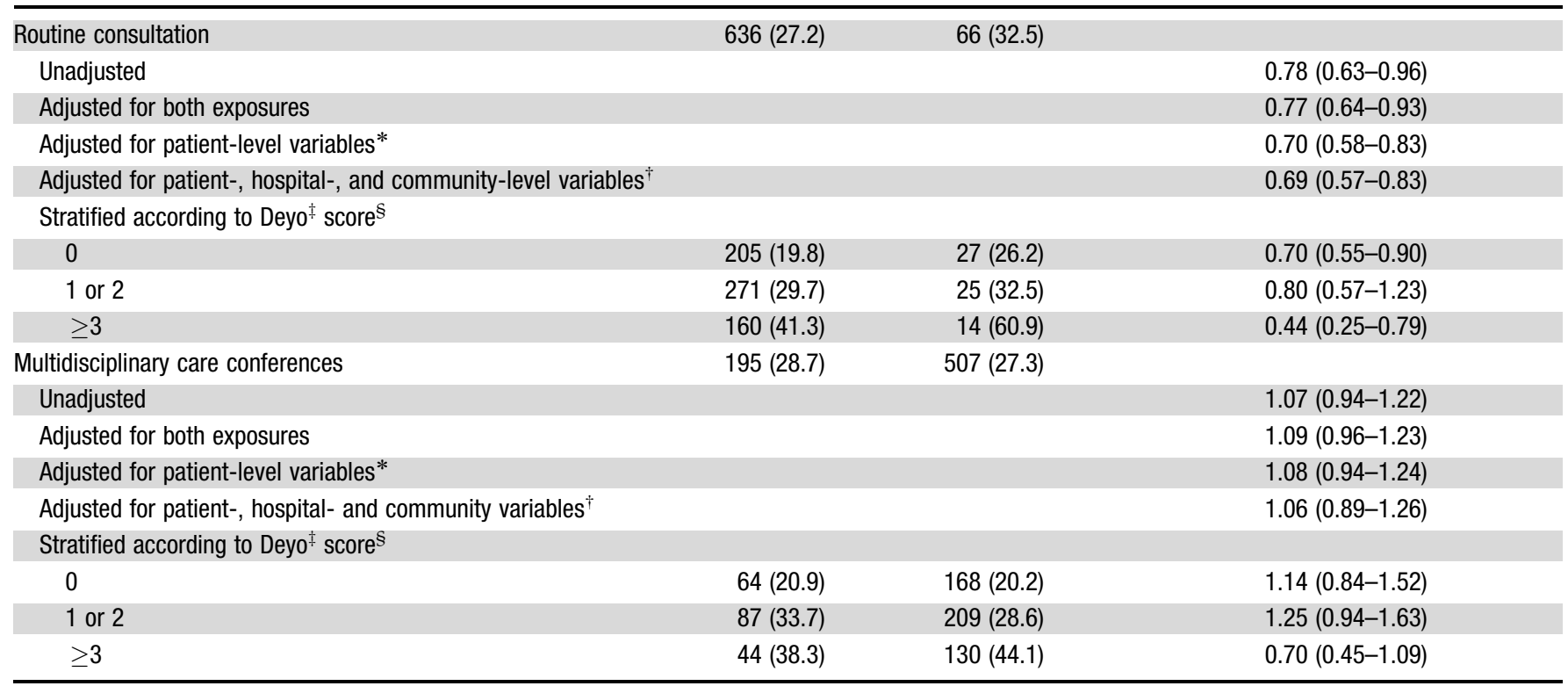

* Adjusted for age, International Classification of Diseases, Ninth Revision-Based Injury Severity Score (ICISS), and Deyo category.

${ }^{\dagger}$ Adjusted for age, ICISS, Deyo category, median household income, population proportion aged 65 and older, trauma center status, and annual hip fracture volume.

${ }^{\ddagger}$ Deyo score quantifies comorbid burden, and ranges from 0 to 31, with a score of 0 indicating no comorbidity, a score of 1 to 2 indicating moderate comorbid burden, and a score of 3 or more indicating severe comorbid burden.

${ }^{\S}$ Stratified for Deyo category and adjusted for age, ICISS, median household income, population proportion aged 65 and older, trauma center status, and annual hip fracture volume.

injuries and treated in an inpatient setting where surgeon consultation with medicine specialists is routine than for patients not treated in such an environment, even after adjusting for differences in injury severity and comorbid burden for individual patients and after accounting for other potentially influential hospital characteristics. Although all-cause mortality in the year after injury was high, approximately $30 \%$ in both groups, a small but clinically important reduction (absolute difference in risk of $5 \%$ ) in mortality appears to be achievable with a relatively inexpensive, feasible, and implementable approach to patient management. The effect of routine consultations appears to be greatest for patients with the greatest burden of comorbid or preexisting conditions- $41 \%$ of these patients died in the first year, compared with $61 \%$ of the patients who did not receive routine consultation. This study also suggests that being treated in an inpatient setting where multidisciplinary care conferences are routine does not appear to affect the likelihood of surviving to 1 year after injury.

It was hypothesized that a routinely multidisciplinary, consultative approach to care for injured older persons would reduce mortality. In this age group aged 67 and older, many patients had multiple medical conditions in addition to the acute injury for which they were being treated, and for many, these preexisting conditions could hamper their recovery from the injury, by impairing the healing process itself or complicating the after-injury rehabilitation care or discharge planning for a recovering patient. ${ }^{43,44}$ Thus, it was thought that, when a surgeon routinely consults with an internist, hospitalist, geriatrician, or primary care physician, he or she might then be better prepared to manage the patient's injury problem, as well as being made more aware of concurrent medical conditions that might hamper recovery. Only a single Oregon hospital had access to a geriatrician for such consultations, so consultations with other medicine or hospitalist specialists was focused on. Previous studies of the effect of hospitalist management showed some evidence of lower mortality $22-24$ of similar magnitude to these findings in general medical patients. One study also reported a 3\% reduction in in-hospital mortality with orthopedist and geriatrician comanagement of older orthopedic patients. ${ }^{28} \mathrm{~A}$ study comparing mortality for patients treated by hospitalists with patients not treated by hospitalists reported ORs of $0.71,0.75$, and 0.79 for in-hospital and 30- and 60-day mortality, respectively. ${ }^{22}$ Another study also found lower mortality for patients treated by hospitalists 30 and 60 days after hospitalization $(\mathrm{OR}=0.82$ and 0.85 , respectively) but noticed no effect on mortality at 1 year. ${ }^{23}$ Unlike these previous studies, which focused on general medical patients of all ages, the current study focused specifically on a cohort of elderly patients and the effect of multidisciplinary management of their injuries. Although this study was not able to identify the precise mechanism by which routine consultation affects survival, a positive association was found.

It was also hypothesized that routine multidisciplinary care conferences involving discharge planning, rehabilitation 
specialists (physical therapy, occupational therapy, or both), and nursing might similarly affect survival outcomes. Patients for whom all their medical and psychosocial needs are considered in this multidisciplinary fashion would, it was speculated, have more-successful transitions from the hospital and would be more likely to survive the first year after their injury, although no association was found between multidisciplinary care conferences and 1-year survival. Collaborations between the ancillary care providers and discharge planning or social work do not appear to matter to survival as much as medical management and collaboration between physicians.

Previous researchers have also studied the associations between clinical interventions in the form of multidisciplinary collaborations and clinical outcomes; interventions such as specialized geriatric care units ${ }^{18,45}$ or interdisciplinary "orthogeriatric" units ${ }^{28,46}$ were associated with shorter length of stay, fewer complications, and better functional outcomes, although such specialized units are not feasible for small or rural hospitals, where the total volume of appropriate patients would probably be insufficient to support a specialized unit. Thus, the current study focused on potentially modifiable factors that might influence survival and that any hospital could potentially implement.

\section{Limitations}

This study was subject to some important methodological limitations. The primary limitation of this study is that it was not possible to determine whether a specific patient definitively received the exposure to routine consultation or multidisciplinary care conferences. Thus, some of the subjects may have been misclassified with regard to their exposure status. The exposure groups as defined did not appear to differ with regard to any relevant patient-level characteristics, such as comorbid conditions or injury severity. If misclassification did not systematically favor one group over another, as defined according to specific patient characteristics, such as age, sex, comorbid conditions, or injury severity, then an attenuation of the association would be expected, compared with what it might be if misclassification did not occur. Thus, this possible misclassification was considered to impose a conservative bias.

The accuracy of the classification of hospitals is vulnerable to error, because it was based on charge nurse report, not direct observation or measurement. It was attempted to minimize such error by categorizing any hospital for which a response seemed to indicate any deviation from routine consultation or multidisciplinary care conferences based on patient-level variations as not having routine processes. If there seemed any doubt, patients treated at that facility were considered to be "unexposed," resulting in a more-conservative estimate of the possible associations. Additionally, a few of the hospitals surveyed had multiple units within which these patients might have been treated, and it is possible that the full variability within the hospital was not captured. Nevertheless, most of the hospitals in Oregon are small and have only one or two medical-surgical units, with nursing staff shared across both units. It was attempted to minimize the bias associated with within-hospital variability by explicitly seeking information about the unit within which the cases were "most likely" to be treated. The analytical methods, accounting for unmeasured within-hospital correlations, were also chosen to help minimize possible bias.

Despite being a population-based cohort, the study group was homogeneous with regard to race, injury type, and severity. The restriction according to injury type was helpful in compensating for the lack of physiological data in assessing injury severity. However, although the distribution of sex and race in the cohort reflects the demographics of the state from which the cohort was drawn, this homogeneity impairs the generalizability of the results to settings with more-diverse demographic profiles. Replication of the results in a different setting would lend credence to the findings.

Finally, the outcome measure, all-cause mortality by 1 year after injury, was a common outcome, with approximately $28 \%$ of the cohort having died by the end of the study period. The method of estimating the association between the exposures and outcomes, using logistic regression methods, will tend to overestimate the relative risk in the setting of a common outcome, in which the outcome occurs in more than $10 \%$ of the cohort. ${ }^{47}$ Caution in interpreting the resulting ORs must be taken. The results indicate lower relative odds of dying by 1 year after injury but should not be interpreted analogously to a relative risk. Attention must also be paid to the relative difference in the proportions of subjects who had the outcome across the exposure groups.

\section{CONCLUSIONS}

Elderly patients with lower extremity orthopedic injuries requiring hospitalization may be more likely to survive their first year after injury if treated in hospital units for which surgeon consultation with medical providers such as hospitalists, internists, or the patient's primary care physician is routine than patients treated in other hospitals. Although causality cannot be asserted without more-detailed understanding of the mechanism by which such consultations are associated with lower mortality, a potential procedure change that any hospital, regardless of size, rurality, or resource levels, could implement and that may have a measurable effect on important patient outcomes, may have been identified.

\section{ACKNOWLEDGMENTS}

Conflict of Interest: The editor in chief has reviewed the conflict of interest checklist provided by the authors and has determined that the authors have no financial or any other kind of personal conflicts with this paper.

Author Contributions: All authors contributed to the development of the study concept and design. ALA and JRH were primarily involved in acquiring the Medicare data. ALA was responsible for conducting the hospital surveys and gathering other publicly available data from organization websites. ALA was primarily responsible for the analysis of the data, with input from all other coauthors. All authors were involved in the final interpretation of the data. All authors contributed to the preparation of the final manuscript.

Sponsor's Role: None.

\section{REFERENCES}

1. Cummings SR, Nevitt MC, Browner WS et al. Risk factors for hip fracture in white women. Study of Osteoporotic Fractures Research Group. N Engl J Med 1995;332:767-773. 
2. Magaziner J, Simonsick EM, Kashner TM et al. Predictors of functional recovery one year following hospital discharge for hip fracture: A prospective study. J Gerontol 1990;45:M101-M107.

3. Inaba K, Goecke M, Sharkey $P$ et al. Long-term outcomes after injury in the elderly. J Trauma 2003;54:486-491.

4. Koval KJ, Skovron ML, Aharonoff GB et al. Predictors of functional recovery after hip fracture in the elderly. Clin Orthop 1998;348:22-28.

5. Magaziner J, Fredman L, Hawkes W et al. Changes in functional status attributable to hip fracture: A comparison of hip fracture patients to communitydwelling aged. Am J Epidemiol 2003;157:1023-1031.

6. Office of Technology Assessment USC. Hip Fracture Outcomes in People Age 50 and Over-Background Paper, OTA-BP-H-20. Washington, DC: U.S. Government Printing Office, 1994.

7. Champion HR, Sacco WJ, Copes WS et al. A revision of the Trauma Score. J Trauma 1989;29:623-629.

8. Finelli FC, Jonsson J, Champion HR et al. A case control study for major trauma in geriatric patients. J Trauma 1989;29:541-548.

9. Gubler KD, Davis R, Koepsell T et al. Long-term survival of elderly trauma patients. Arch Surg 1997;132:1010-1014.

10. Morris JA Jr., MacKenzie EJ, Damiano AM et al. Mortality in trauma patients: The interaction between host factors and severity. J Trauma 1990;30:1476-1482.

11. Oreskovich MR, Howard JD, Copass MK et al. Geriatric trauma: Injury patterns and outcome. J Trauma 1984;24:565-572.

12. Perdue PW, Watts DD, Kaufmann CR et al. Differences in mortality between elderly and younger adult trauma patients: Geriatric status increases risk of delayed death. J Trauma 1998;45:805-810.

13. Tornetta P III, Mostafavi H, Riina J et al. Morbidity and mortality in elderly trauma patients. J Trauma 1999;46:702-706.

14. Cooper C, Atkinson EJ, Jacobsen SJ et al. Population-based study of survival after osteoporotic fractures. Am J Epidemiol 1993;137:1001-1005.

15. Fisher ES, Baron JA, Malenka DJ et al. Hip fracture incidence and mortality in New England. Epidemiology 1991;2:116-122.

16. Myers AH, Robinson EG, Van Natta ML et al. Hip fractures among the elderly: Factors associated with in-hospital mortality. Am J Epidemiol 1991;134:1128-1137.

17. Magaziner J, Simonsick EM, Kashner TM et al. Survival experience of aged hip fracture patients. Am J Public Health 1989;79:274-278.

18. Landefeld CS, Palmer RM, Kresevic DM et al. A randomized trial of care in a hospital medical unit especially designed to improve the functional outcomes of acutely ill older patients. N Engl J Med 1995;332:1338-1344.

19. Druss BG, Bradford WD, Rosenheck RA et al. Quality of medical care and excess mortality in older patients with mental disorders. Arch Gen Psychiatry 2001;58:565-572

20. Fine JM, Fine MJ, Galusha D et al. Patient and hospital characteristics associated with recommended processes of care for elderly patients hospitalized with pneumonia: Results from the Medicare quality indicator system pneumonia module. Arch Intern Med 2002;162:827-833.

21. Petrik DW, McCready DR, Sawka CA et al. Association between extent of axillary lymph node dissection and patient, tumor, surgeon, and hospital factors in patients with early breast cancer. J Surg Oncol 2003;82:84-90.

22. Auerbach AD, Wachter RM, Katz P et al. Implementation of a voluntary hospitalist service at a community teaching hospital: Improved clinical efficiency and patient outcomes. Ann Intern Med 2002;137:859-865.

23. Meltzer D, Manning WG, Morrison J et al. Effects of physician experience on costs and outcomes on an academic general medicine service: Results of a trial of hospitalists. Ann Intern Med 2002;137:866-874.

24. Tenner PA, Dibrell H, Taylor RP. Improved survival with hospitalists in a pediatric intensive care unit. Crit Care Med 2003;31:847-852.

25. Lindenauer PK, Rothberg MB, Pekow PS et al. Outcomes of care by hospitalists, general internists, and family physicians. N Engl J Med 2007;357:2589-2600.

26. Phy MP, Vanness DJ, Melton LJ III et al. Effects of a hospitalist model on elderly patients with hip fracture. Arch Intern Med 2005;165:796-801.
27. Huddleston JM, Long KH, Naessens JM et al. Medical and surgical comanagement after elective hip and knee arthroplasty: A randomized, controlled trial. Ann Intern Med 2004;141:28-38.

28. Fisher AA, Davis MW, Rubenach SE et al. Outcomes for older patients with hip fractures: The impact of orthopedic and geriatric medicine cocare. J Orthop Trauma 2006;20:172-8; discussion 179-180.

29. Marcantonio ER, Flacker JM, Wright RJ et al. Reducing delirium after hip fracture: A randomized trial. J Am Geriatr Soc 2001;49:516-522.

30. Population Research Center, Portland State University 2002 Oregon Population Report [on-line]. Available at http://www.pdx.edu/prc/annualorpopula tion.html Accessed March 25, 2008.

31. Oregon Hospital Utilization [on-line]. Available at http://www.oahhs.org/ data/utilization.php Accessed March 25, 2008.

32. Oregon Trauma System Hospitals. Department of Human Services, State of Oregon, Oregon Trauma Program [on-line]. Available at http://egov.oregon. gov/DHS/ph/ems/trauma/docs/hosplist.pdf Accessed March 25, 2008.

33. Oregon Health Policy \& Research. Oregon Hospital Quality Indicator Project, 2004: Hip Fracture [on-line]. Available at http://www.oregon.gov/OHPPR/ HQ/docs/IQI2004_HIPF.pdf Accessed July 2005.

34. Zhang JX, Iwashyna TJ, Christakis NA. The performance of different lookback periods and sources of information for Charlson comorbidity adjustment in Medicare claims. Med Care 1999;37:1128-1139.

35. Charlson ME, Pompei P, Ales KL et al. A new method of classifying prognostic comorbidity in longitudinal studies: Development and validation. J Chronic Dis 1987;40:373-383.

36. Deyo RA, Cherkin DC, Ciol MA. Adapting a clinical comorbidity index for use with ICD-9-CM administrative databases. J Clin Epidemiol 1992;45: 613-619.

37. Osler T, Rutledge R, Deis J et al. ICISS: An International Classification of Disease-9 based injury severity score. J Trauma 1996;41:380-386; discussion 386-388.

38. Rutledge R, Hoyt DB, Eastman AB et al. Comparison of the Injury Severity Score and ICD-9 diagnosis codes as predictors of outcome in injury: Analysis of 44,032 patients. J Trauma 1997;42:477-87; discussion 87-89.

39. Rutledge R, Osler T. The ICD-9-based illness severity score: A new model that outperforms both DRG and APR-DRG as predictors of survival and resource utilization. J Trauma 1998;45:791-799.

40. Rutledge R, Osler T, Emery $S$ et al. The end of the Injury Severity Score (ISS) and the Trauma and Injury Severity Score (TRISS): ICISS, an International Classification of Diseases, ninth revision-based prediction tool, outperforms both ISS and TRISS as predictors of trauma patient survival, hospital charges, and hospital length of stay. J Trauma 1998;44:41-49.

41. Rural hospitals. Oregon Health \& Science University [on-line]. Available at http://www.ohsu.edu/ohsuedu/outreach/oregonruralhealth/hospitals/rural hospitals.cfm Accessed March 25, 2008.

42. Diggle PJ, Heagerty PJ, Liang K-Y et al. Analysis of Longitudinal Data, 2nd Ed. Oxford: Oxford University Press, 2002.

43. Taffet GE. Physiology of aging. In: Cassel CK, Leipzig RM, Cohen HJ, Larson EB, Meier DE, Capello CF, editors. Geriatric Medicine: An Evidence-Based Approach, 4th Ed. New York: Springer-Verlag, 2003, pp 27-35.

44. Tangarorang GL, Kerins GJ, Besdine RW. Clinical approach to the older patient: An overview. In: Cassel CK, Leipzig RM, Cohen HJ, editors. Geriatric Medicine: An Evidence-Based Approach, 4th Ed. New York: Springer-Verlag, 2003, pp 149-162.

45. Adunsky A, Lusky A, Arad M et al. A comparative study of rehabilitation outcomes of elderly hip fracture patients: The advantage of a comprehensive orthogeriatric approach. J Gerontol A Biol Sci Med Sci 2003;58A:542-547.

46. Zuckerman JD, Sakales SR, Fabian DR et al. Hip fractures in geriatric patients. Results of an interdisciplinary hospital care program. Clin Orthop 1992, 213-225.

47. McNutt LA, Wu C, Xue X et al. Estimating the relative risk in cohort studies and clinical trials of common outcomes. Am J Epidemiol 2003;157:940-943. 